\title{
Interpretation, Characterization and Importance of the Internal Salt Cycles for Seismic Processes: a Santos Basin Example
}

Rodrigo Pontes (Petrobras, UFF), Alexandre Maul (Petrobras, UFF) \& Cleverson Guizan (UFF)

Copyright 2019, SBGf - Sociedade Brasileira de Geofísica

This paper was prepared for presentation during the $16^{\text {th }}$ International Congress of the Brazilian Geophysical Society held in Rio de Janeiro, Brazil,19-22August 2019.

Contents of this paper were reviewed by the Technical Committee of the $16^{\text {th }}$ International Congress of the Brazilian Geophysical Society and do not necessarily represent any position of the SBGf, its officers or members. Electronic reproduction or storage of any part of this paper for commercial purposes without the written consent of the Brazilian Geophysical Society is prohibited.

\section{Abstract}

Along with the discovery of the Pre-Salt reservoirs in Santos Basin, the necessity to understand and model the large salt bodies in a more realistic way became quite clear, especially for seismic purposes. However, a closer look to what is so-called only by "Salt" reveals an enormous depositional complexity, formed by cycles that are directly related to the basin environmental and geological history. One of the industry major challenges is to model these salt bodies using the available data since the climate mechanisms that regulate salt deposition and preservation are yet to be fully understood. Nowadays, it is known that the balance of the mechanisms that regulate the salt precipitation is very delicate and that little climate changes may alter the way salt minerals precipitate and their preservation. According to analog and experimental data, there is a defined precipitation order, which, in general, behaves like this: carbonates, gypsium or anhydrite, halite, and complex salts (tachyhydrite, carnalite, sylvite). It is possible to say that geological and environmental factors control salt precipitation and preservation together and that the major cycles described in literature are trackable in the studied area and that the incorporation of their properties and geometry on models produces better results. The main contribution of this work is to interpret and characterize the internal salt cycles using seismic data, comparing with the well information and evaluate the incorporation importance of this task for seismic processes.

\section{Introduction}

During the Aptian period, the area that is currently is named as the Santos Basin (SE Brazil) has been characterized as a restricted sea for a period of about 9 m.y., cut off from oceanic circulation by the Rio Grande Rise (Figure 2). This restricted sea had the perfect conditions for the salt precipitation: high evaporation rates, arid climate, and little fresh water intake. As per Gamboa et al. (2009), based on seismic interpretation, the Ariri Formation has four major salt cycles. Those cycles were preserved in the following order: (1) A thick basal layer of halite (2) A layer with anhydrite on the base followed by halite and other salts (3) a thinner layer of halite (4) a thinner layer presenting the same sequence described in (2). The same authors cite Freitas (2006) recognition of other minor cycles within these four major cycles. Each minor cycle, from base to top, is composed of anhydrite, halite, complex salts, another layer of halite and anhydrite. It is important to notice that the complex salts may not be always present in the cycles since its precipitation and preservation are only met at very specific climatic and environmental conditions. They tend to occur on central portions of brine bodies, during an extremely arid climate and with little or inexistent freshwater input.

The Ariri Formation has always been simplified in seismic velocity modelling as a homogeneous geological feature, typically using the halite properties. These velocity models are used for seismic processing, time-depth conversion and as low-frequency models for inversion and geomechanic studies. The simplification of the evaporites properties affects seismic migration, reservoir depth prediction and well planning, causing important budget losses for the companies in the oil and gas business.

Recently several efforts are approaching the problem and detailing the evaporite section, aiming to create more accurate velocity models for any seismic usage (Maul et al., 2015 and other papers). In order to complement these studies, it is crucial to understand the salt basin cycles depositional dynamics as well as their structural behavior. Therefore, enabling one to go beyond seismic data when interpreting higher frequency cycles. Since the major cycles have been mapped for the area, the small cycles can be inferred by using well data information and modeling, such as seismic inversion or any geostatistical approach.

In this research, we performed an interpretation and characterization of the main salt cycles in the area of study, compared them with the information we got from the wells and tried to characterize the minor salt cycles. After that, we evaluate the importance of the incorporation of these results for seismic processes. 
Method

This work is part of a master's research and focus on the identification of the major and minor cycle's boundaries using a basic well log suite (DT, RHOB, GR) of 10 wells. A1D synthetic modelling to predict the seismic response of the boundaries and, whenever possible, these boundaries were mapped (Figure 3). The attribute and thickness maps calculations enables better understanding of the geometrical relations and textural variations of the salt cycles. Many of the minor cycles do not have a seismic reflection response, but it is sometimes possible to infer their existence based on the depositional context and the relation to the major cycles. By mapping as many cycles as possible, we have a better understanding of their geometrical relation and spatial distribution of each cycle.

\section{Available Data}

The data used in this research is a piece of seismic data (around $100 \mathrm{~km} 2$ ) from the Sapinhoá Field in Santos Basin, offshore Brazil and 10 drilled well. All the information were provided by the Brazilian National Petroleum Agency (ANP).

\section{Results, Conclusions and Future Works}

The seismic data and 1D modeling analysis show that it is possible to identify and to map the four major cycles described in Freitas (2006) as well as some minor cycle boundaries. Experimental and analog data suggests that little changes in the variables that balance the precipitation/deposition system can have dramatic impact on the composition of the evaporite layers. For instance, a global change that makes the climate water can prevent the preservation of complex salts. On top of that, diagenetic and geomechanical changes are obviously important but are still not contemplated in this study, allowing further researches and discussions.

The preliminary results of this study, as we are still in the first year of the current research, indicate that the cycles can be defined as a predictable succession of salts that are deposited within specific climate conditions. A regular salt deposition for seawater, without any climate change, is: anhydrite or gypsium, halite, and the complex salts. The main cycles described in literature are trackable, at least in the study area (Figure 4).

In the development of this investigation we will focus on the impact of the salt velocity modelling, including the cited cycles, over the seismic illumination study, seismic migration and seismic inversion. We expect considerably better results in these processes, as well as for the timedepth conversion, including the uncertainties analysis for both: signal quality and positioning.

\section{Acknowledgments}

The authors would like to thank ANP (Agência Nacional do Petróleo) and Petrobras for providing the data and permission to develop and support the publication of the results of this work.

\section{References}

Amaral, P.J., Maul, A., Falcão, L., González, M. \& González, G. 2015. Estudo estatístico da velocidade dos sais na camada evaporítica na bacia de santos. 14th International Congress of the Brazilian Geophysical Society, Rio de Janeiro, RJ, Brazil. doi: 10.1190/sbgf2015-131.

Freitas J.T.R. 2006. Ciclos Deposicionais Evaporíticos da Bacia de Santos: Uma Análise Cicloestratigráfica a partir de Dados de 2 Poços e de Traços de Sísmica. Porto Alegre: UFRS, 160 p. Dissertação (Mestrado);

Gamboa, L.A.P., Machado, M.A.P., Silveira, D.P., Freitas, J.T.R. \& Silva, S.R.P. 2008. Evaporitos estratificados no Atlântico Sul: Interpretação Sísmica e Controle Tectono-Estratigráfico na Bacia de Santos. In Sal: Geologia e Tectônica. Primeira Edição. Beca Edições Ltda. São Saulo - SP - Brazil (p. 340-359).

Kukla P.A., Mohriak W.U., Strozyk F.; 2017. South Atlantic salt basins - Witnesses of complex passive margin evolution. In Gondwana Research (2018) (p. 41 57). doi: 10.1016/j.gr.2017.03.012.

Maul A., Jardim F., Falcão L., \& González G. 2015. Observing Amplitude Uncertainties for a Pre-Salt Reservoir Using Illumination Study (Hit-Maps). ( $77^{\text {th }}$ EAGE Conference \& Exhibition), Madrid, Spain. doi: 10.3997/2214-4609.201412921

Mohriak W., Szatmari P \& Anjos S.M.C. (eds.). 2009. Sal: Geologia e Tectônica. Primeira Edição. Beca Edições Ltda. São Saulo - SP - Brazil.

Pontes R., Maul A. \& Guizan C. 2018. Considerações Sobre os Ciclos Evaporíticos da Bacia de Santos. Paper presented at the Congresso Brasileiro de Geologia. doi: 10.13140/RG.2.2.10616.29443. 


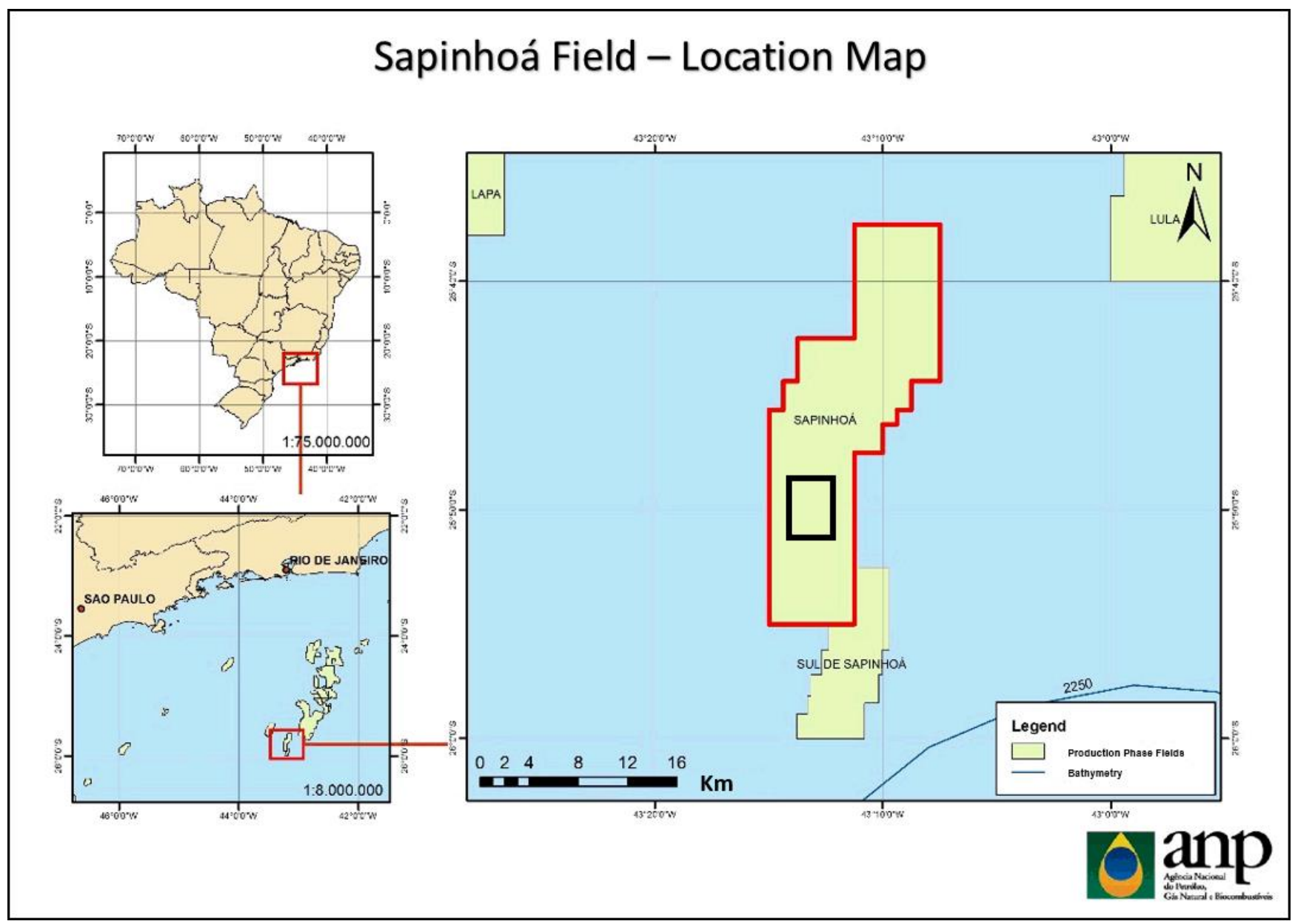

Figure 1: Sapinhoá Field is located in the central portion of Santos Basin, approximately $290 \mathrm{~km}$ from Rio de Janeiro city. The average water depth is $2,140 \mathrm{~m}$. The black polygon represents the 3D seismic interpreted area used for this work. 

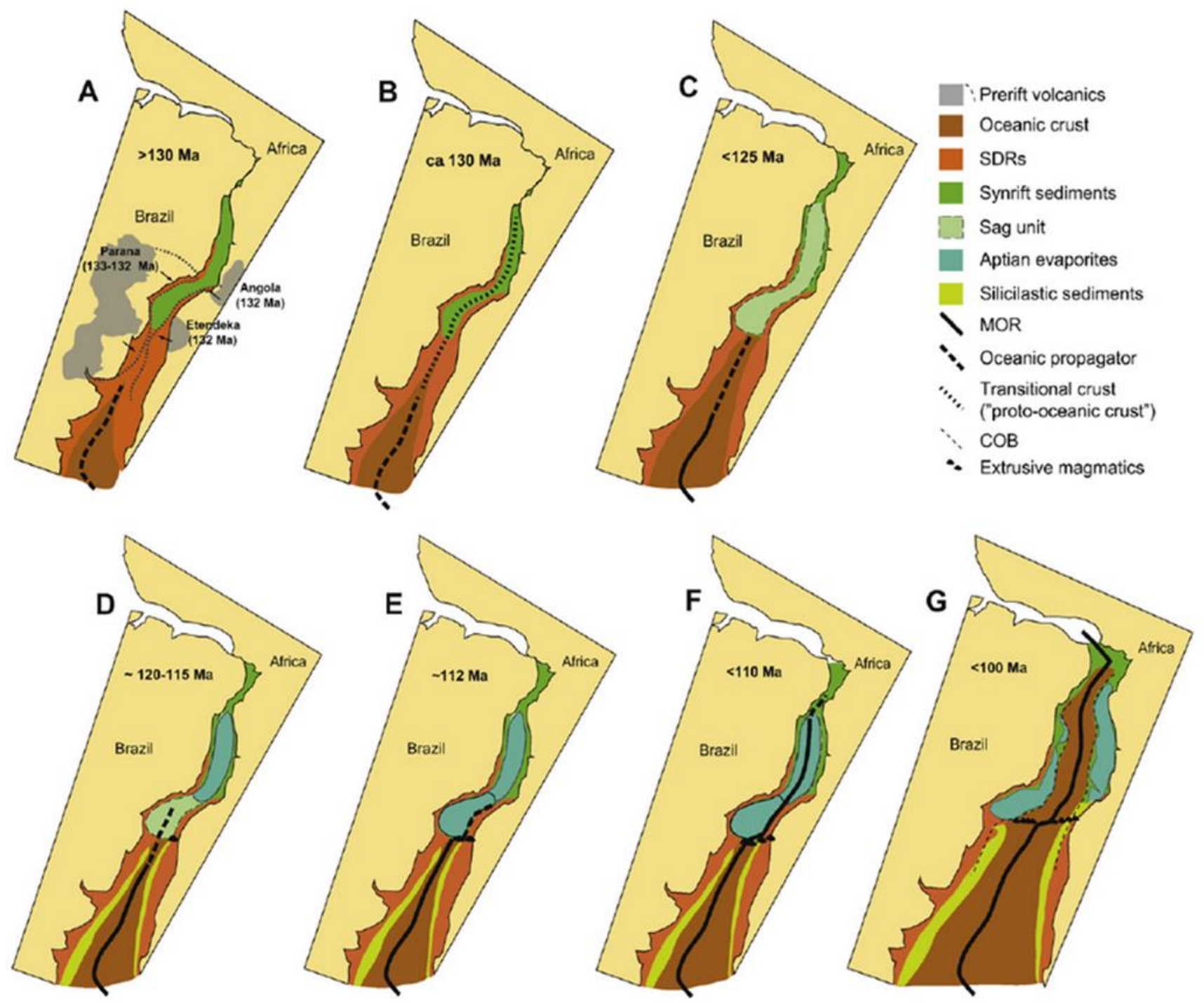

Figure 2: Schematic geodynamic evolution of South Atlantic showing the separation of South American and African continents during the Aptian, creating the necessary condition for deposition of evaporites (Kukla et al. 2017). 


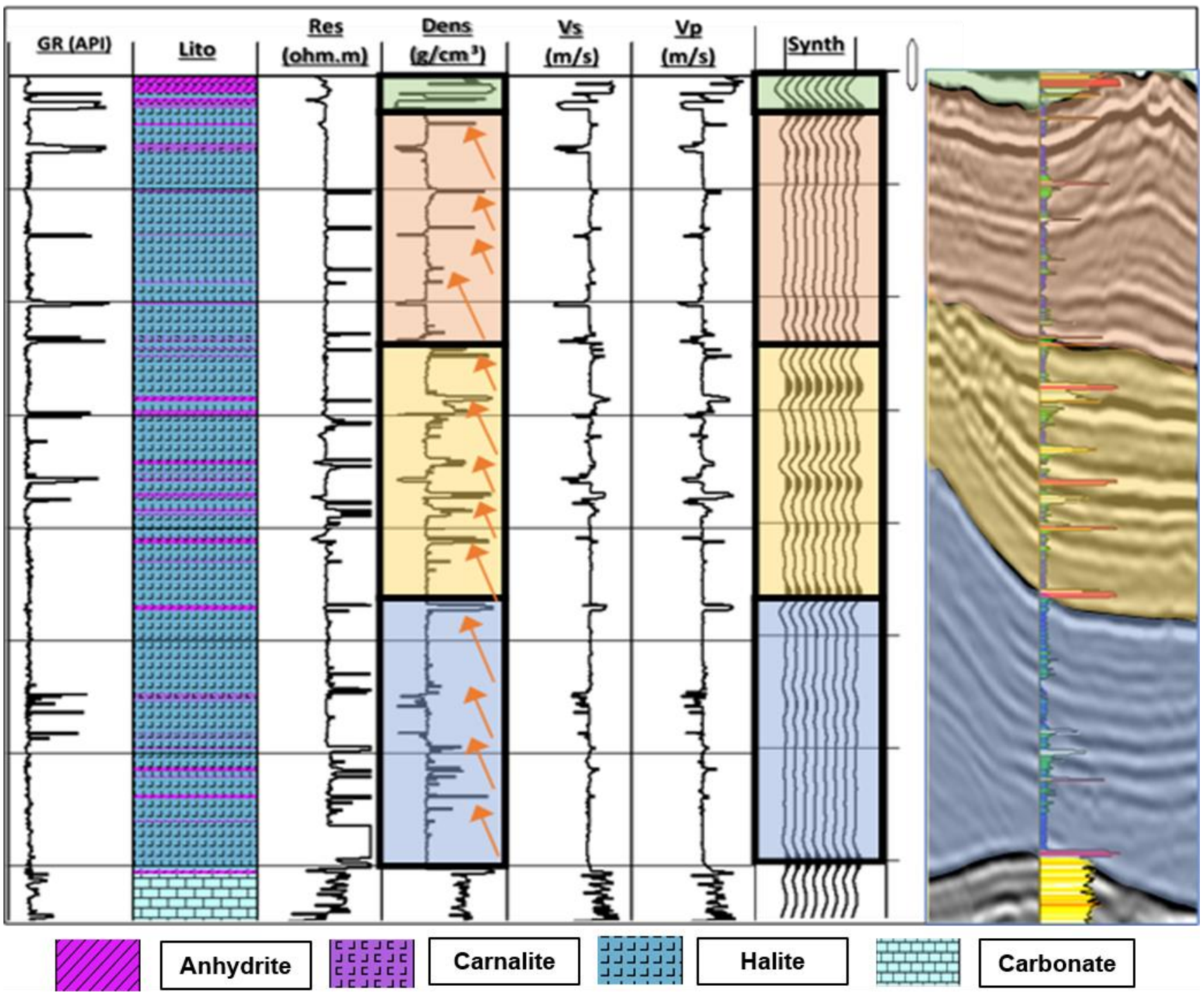

Figure 3: Basic well log suite of the well 3-BRSA-923A-SPS and the results of the seismic signal modeling analysis. It is possible to track the four major cycles as well as minor cycles within them. The colored sections are the major cycles and the arrows indicate some minor cycles identifiable in the well log. The synthetic track shows that not every minor cycle is trackable with this frequency content. Freitas (2006) suggests that these minor cycles correlate with orbital variations (Milankovitch cycles). Adapted from Pontes et al. (2018). 


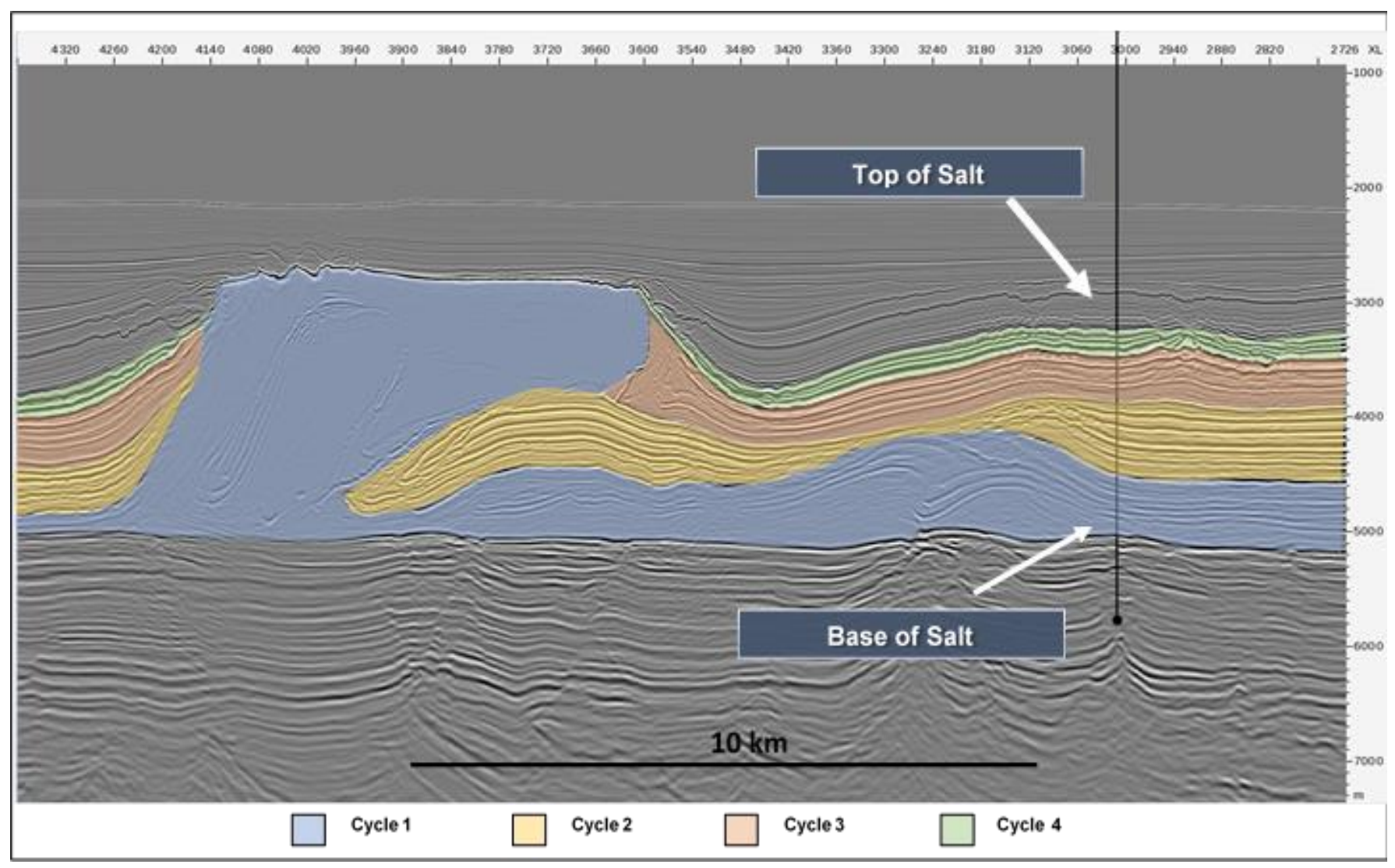

Figure 4: Seismic section in depth representing the mapped four major cycles described by Gamboa et al. (2009) and the well 3-BRSA923A-SPS. It is important to notice the seismic facies variation between cycles and the structural complexity. 